\title{
Algumas consequências econômicas da implantação do Cadastro Ambiental Rural: o caso de Municípios do Noroeste Gaúcho, Brasil
}

Some economic consequences of the implementation of the Rural Environmental

Registry: the case of Municipalities in the Northwest of Rio Grande do Sul, Brazil

Algunas consecuencias económicas de la implementación del Registro Ambiental Rural: el caso de los Municipios en el Noroeste de Rio Grande do Sul, Brasil

Recebido: 19/05/2020 | Revisado: 20/05/2020 | Aceito: 25/05/2020 | Publicado: 03/06/2020

Argemiro Luís Brum

ORCID: https://orcid.org/0000-0002-8763-9514

Universidade Regional do Noroeste do Estado do Rio Grande do Sul, Brasil

E-mail: argelbrum@unijui.edu.br

Maria Alice da Costa Beber Goi

ORCID: https://orcid.org/0000-0002-5246-3360

Universidade Regional do Noroeste do Estado do Rio Grande do Sul, Brasil

E-mail: mariaalicegoi@hotmail.com

Nelson José Thesing

ORCID: https://orcid.org/0000-0001-7123-0717

Universidade Regional do Noroeste do Estado do Rio Grande do Sul, Brasil

E-mail: nelson.thesing@unijui.edu.br

Luciana Moro de Souza

ORCID: https://orcid.org/0000-0003-3838-4540

Universidade Regional do Noroeste do Estado do Rio Grande do Sul, Brasil

E-mail: luciana.moro@unijui.edu.br

\section{Resumo}

O presente trabalho busca identificar algumas consequências imediatas, da implantação do

Cadastro Ambiental Rural. Trata-se de um Projeto de Lei, efetivado após várias prorrogações, na esperança de os produtores rurais se adequarem ao que a legislação estabeleceu, ou seja, à 
realização do cadastramento. Os primeiros impactos identificados na aplicação da Lei, para os que não realizaram o cadastramento de suas propriedades rurais, vieram sob a forma de negativas de financiamentos agrícolas, exigência apontada pelas agências bancárias, bem como a não autorização da contratação de seguro agrícola. Para verificar as consequências, caminho metodólogo conta com a pesquisa qualitativa, entrevistas semiestruturadas, com profissionais que atuam diretamente com os produtores rurais e que estão familiarizados com o Cadastro Ambiental. Esse processo contribuiu para uma melhor compreensão dos problemas enfrentados pelos produtores rurais, quando da realização ou não do Cadastro. Os resultados da pesquisa apontam que as propriedades rurais terão profundas perdas em suas receitas, fruto da implantação do Cadastro, especialmente, na redução das áreas plantadas. De outro lado, uso sustentável e racional dos recursos naturais existentes implicará na redução da poluição do ar, água e solo, preservação da biodiversidade, que devem favorecer o desenvolvimento socioeconômico das futuras gerações.

Palavras-chave: Cadastro ambiental rural; Área de preservação; Reserva legal.

\section{Abstract}

The present research seeks to identify some immediate consequences of the implementation of the Rural Environmental Registry. It is a Bill, carried out after several extensions, in the hope that rural producers will adapt to what the legislation established, that is, to register. The first impacts identified in the application of the Law, for those who did not register their rural properties, came in the form of negative agricultural financing, a requirement pointed out by bank agencies, as well as the non-authorization of contracting agricultural insurance. To verify the consequences, a methodological approach relies on qualitative research, semistructured interviews, with professionals who work directly with rural producers and who are familiar with the Environmental Registry. This process contributed to a better understanding of the problems faced by rural producers, when the Registration was carried out or not. The results of the research indicate that rural properties will have profound losses in their revenues, as a result of the implementation of the Register, especially in the reduction of planted areas. On the other hand, sustainable and rational use of existing natural resources will imply a reduction in air, water and soil pollution, preservation of biodiversity, which should favor the socioeconomic development of future generations.

Keywords: Rural environmental Registry; Preservation area; Legal reserve. 


\section{Resumen}

El presente trabajo busca identificar algunas consecuencias inmediatas de la implementación del Registro Ambiental Rural. Es un proyecto de ley, implementado después de varias extensiones, con la esperanza de que los productores rurales se adapten a lo que la legislación ha establecido, es decir, para registrarse. Los primeros impactos identificados en la aplicación de la Ley, para aquellos que no registraron sus propiedades rurales, vinieron en forma de financiamiento agrícola negativo, un requisito señalado por las agencias bancarias, así como la no autorización de contratar seguros agrícolas. Para verificar las consecuencias, un enfoque metodológico se basa en la investigación cualitativa, entrevistas semiestructuradas, con profesionales que trabajan directamente con productores rurales y que están familiarizados con el Registro Ambiental. Este proceso contribuyó a una mejor comprensión de los problemas que enfrentan los productores rurales, cuando el registro se realizó o no. Los resultados de la encuesta indican que las propiedades rurales tendrán profundas pérdidas en sus ingresos, como resultado del establecimiento del Cadastro, especialmente en la reducción de las áreas plantadas. Por otro lado, el uso sostenible y racional de los recursos naturales existentes implicará una reducción de la contaminación del aire, el agua y el suelo, la preservación de la biodiversidad, lo que debería favorecer el desarrollo socioeconómico de las generaciones futuras.

Palabras clave: Registro ambiental rural; Área de preservación, Reserva legal.

\section{Introdução}

Ao buscar a identificação das consequências imediatas, pela implantação do Cadastro Ambiental Rural, que opera a efetivação de um Projeto de Lei, após várias prorrogações, para que os produtores rurais se adequarem a legislação, ou seja, à realização do cadastramento. Assim, para ampliar as lentes, busca-se inicialmente um olhar sobre as políticas públicas, que podem ser identificadas por quatro formas distintas: as políticas distributivas, que visam oportunizar benefícios à população por meio da distribuição de serviços; as políticas redistributivas, que consistem na administração dos recursos financeiros, outros valores às diversas classes sociais; as políticas regulatórias, que apontam o cumprimento das normas em decretos e portaria; e, por fim, as políticas constitutivas, que orientam a estrutura metodológica do processo político, que contempla as negociações entre as políticas distributivas, redistributivas e regulatórias segundo Souza (2007). 
Já para Lynn (1980), o conceito de políticas públicas passa a ser um conjunto de ações operadas pelo governo que produzirão efeitos na sociedade de forma particular. Portanto, as políticas públicas colocam o governo em movimento, em ação, ao propor mudanças, ou reordenar ações. Em outras palavras, para Souza (2003, p.26) "o processo de formulação de política pública é aquele através do qual os governos traduzem seus propósitos em programas e ações". Assim, esse processo buscar produzir resultados desejados na sociedade.

Portanto, a presente pesquisa busca verificar as políticas regulatórias, que trilham o cumprimento das normas, decretos, portarias que integram a constituição de uma política pública que fundamentam a "soma das atividades dos governos, que agem diretamente ou através de delegação, influenciando a vida dos cidadãos” segundo Peters (1986, p. 21). Corrobora Kiviniemi (1985) ao apresentar a política pública como um espaço que pode estabelecer vínculo entre o governo e a sociedade e esse vínculo promove uma alteração comportamental nos cidadãos ora voluntária, ora coercitiva.

Assim, a investigação irá verificar a Lei $\mathrm{n}^{\circ}$ 12.651/2012 que indica a necessidade de um novo comportamento dos atores na agricultura, ao apontar a exigência de um cadastro nacional das propriedades rurais. Esse processo aponta inquietações para os agricultores e demais profissionais, que trabalham no setor, ao olhar para o Cadastro Ambiental Rural, Reserva Legal, e Área de Preservação Permanente.

A Lei $\mathrm{n}^{\circ} 12.651 / 2012$ de que trata o Cadastro Ambiental Rural (CAR), em substituição à Lei Federal nº 6.938/81, aponta para algumas necessidades investigativas, entre elas: investimentos necessários para a regularização das propriedades rurais, os desembolsos indiretos que devem ser realizados para que a propriedade esteja enquadrada nas exigências legais de preservação ambiental e quais os valores que deixarão de ser gerados dentro da propriedade ao deixar a área de preservação permanente, conforme exigências da legislação.

A efetivação da Lei $\mathrm{n}^{\circ}$ 12.651/2012 permite investigar o Programa Nacional de Incentivo à Preservação Ambiental que indica aos produtores rurais áreas para preservação, sem que lhe cause perdas na geração de renda na referida área. Porém, o mercado físico de commodities e a bolsa de mercadorias se mostram preocupados frente a efetivação ou não do Cadastro, uma vez que esse passa a ser uma exigência no momento dos financiamentos e dos seguros agrícolas, fato que poderá implicar em redução de áreas cultivadas e, por consequência, em menor geração de renda nas propriedades rurais.

A metodologia utilizada se concentrou em pesquisas bibliográficas, na legislação, em entrevistas semiestruturadas com profissionais que atuam no campo do planejamento e 
orientação agrícola, engenheiros agrícolas e florestais, que vivenciam os efeitos da aplicação da legislação e do cadastro nas propriedades.

\section{Referencial Teórico}

No entender de Borges (2013) o Cadastro Ambiental Rural (CAR) poderá se transformar em um instrumento facilitador da fiscalização ambiental, um mecanismo da gestão das propriedades nela inseridas. $\mathrm{O}$ autor alimenta esse entendimento em função de muitos cadastros em cartório não estabelecerem tanta segurança jurídica quanto um sistema que vai disponibilizar para o público todas as informações referentes àquela área.

Corrobora Francisco Graziano (2012) ao se posicionar a favor do Cadastro Ambiental Rural, ao indicar uma das vantagens da nova lei florestal para facilitar a fiscalização ambiental. Na mesma linha de pensamento Farinaci et al. (2013) apostam no Cadastro. Os autores admitem que o monitoramento de áreas rurais por sensoriamento remoto é, sem dúvida, uma ferramenta importante para a gestão ambiental.

Portanto, o Cadastro poderá oportunizar certa vantagem relacionada ao mercado de cotas de Reserva Legal (RL) por ser uma ferramenta que permite troca de informações e imagens para aqueles que precisam empregar o recurso de Cotas de Reserva Ambiental (CRA's), que são títulos representativos de cobertura vegetal que podem ser utilizados para compensar a falta de RL em outra propriedade, ou seja, aquelas propriedades que possuem déficit de RL podem arrendar ou comprar áreas nativas daquelas que estão com superávit de reserva.

No entender de Camargo (2013), o Cadastro poderá ser uma importante ferramenta no campo da gestão ambiental das propriedades rurais, porém, algumas mudanças poderiam contribuir no processo de seu estabelecimento. Dentre elas está o sistema nacional que o Ministério do Meio Ambiente (MMA) defende com a presença de um técnico para realização do Cadastro. Esse processo poderá permitir que o próprio produtor rural faça sua planta do imóvel com a delimitação do perímetro e das respectivas áreas de conservação.

A perspectiva advinda com o cadastramento indica maior efetivação da seguridade ambiental, não só nas Reservas Legais, mas nas Áreas de Preservação Permanente, nos remanescentes de vegetação nativa, nas Áreas de Uso Restrito e nas áreas consolidadas das propriedades, de acordo com o Programa de Regularização Ambiental (PRA) estabelecido pelo Art. 59 da Lei 12.652/12 e pelo Dec. 7.830/12. 
Tem-se presente que a política ambiental poderá contribuir na promoção de um melhor entrosamento entre o olhar econômico e social, desafiando estudos de abordagem interdisciplinar e de longo prazo na busca do bem-estar material, no entender de Bursztyn \& Bursztyn (2013).

Muitas foram às conferências mundiais realizadas para a defesa do meio ambiente e, a partir delas, foram criadas políticas e orientações comuns a serem tomadas por todos os países para implementação de uma governança global.

Uma das dificuldades para a alteração do sistema de uso de recursos naturais está na política de acumulação de capital que se espalha pelo mundo. Segundo Romeiro

a grande dificuldade para a adoção de uma atitude precavida de buscar estabilizar o nível de consumo de recursos naturais está em que esta estabilização pressupõe uma mudança de atitude que contraria a lógica do processo de acumulação de capital em vigor desde a ascensão do capitalismo (Romeiro, 2001, p.15).

No Brasil, a partir dos anos de 1930, iniciou-se um processo de regulamentação do uso dos recursos ambientais disponíveis no país. A partir daí vários instrumentos regulatórios foram criados, sendo eles: Código de Águas (1934), Código Florestal (1934), Código de Caça e Pesca (1934), Lei de Proteção aos Animais (1934), Política Nacional de Saneamento (1967), Política Nacional de Meio Ambiente - PNMA (1981), Lei de Proteção à Fauna (1988), Plano Nacional de Desenvolvimento Costeiro (1988), entre outros instrumentos de proteção ambiental.

As políticas de proteção ambiental foram sendo criadas e transformadas conforme as necessidades ambientais surgiam, até que em 25 de maio de 2012 foi criado, através da Lei no 12.651/12, o Cadastro Ambiental Rural.

Segundo o Ministério do Meio Ambiente (MMA), Cadastro Ambiental Rural

é um registro eletrônico, obrigatório para todos os imóveis rurais, formando base de dados estratégica para o controle, monitoramento e combate ao desmatamento das florestas e demais formas de vegetação nativa do Brasil, bem como para planejamento ambiental e econômico dos imóveis rurais (MMA, 2020).

Por meio da realização do cadastro ambiental, os proprietários informam ao programa quais são as áreas de preservação permanente e a reserva legal existente em sua propriedade.

Por outro lado, conforme encontrado no site do Senado Federal, a definição de Área de Preservação Permanente está expressa no Código Florestal. 
De acordo com o Código Florestal (Lei no 4.771/65), são consideradas Áreas de Preservação Permanente (APPs) aquelas protegidas nos termos da lei, cobertas ou não por vegetação nativa, com as funções ambientais de preservar os recursos hídricos, a paisagem, a estabilidade geológica, a biodiversidade e o fluxo gênico de fauna e flora, proteger o solo e assegurar o bem-estar das populações humanas (Senado Federal, 2020).

Já Reserva Legal, segundo a mesma fonte, foi redefinida em 2001 através de uma nova MP (2.166-67), sendo que, através dela

reserva legal é "área localizada no interior de uma propriedade ou posse rural, excetuada a de preservação permanente, necessária ao uso sustentável dos recursos naturais, à conservação e reabilitação dos processos ecológicos, à conservação da biodiversidade e ao abrigo e proteção de fauna e flora nativas", restringindo ainda mais as possibilidades de uso dessas áreas (Senado Federal, 2020).

A criação do Cadastro Ambiental Rural tem por finalidade agrupar informações ambientais das propriedades rurais, especialmente em relação à Área de Preservação Permanente e à Reserva Legal, áreas remanescentes e outras formas de vegetação nativa, que estão consolidadas ao longo dos anos. Com esse agrupamento de informações haverá um monitoramento da situação ambiental do país, o controle do uso das áreas, além do planejamento ambiental e econômico, para o fim de combater o desmatamento.

\section{Procedimentos Metodológicos}

Os procedimentos metodológicos do estudo trilham a pesquisa qualitativa, que encontra Lakatos \& Marconi (2012) orientações para verificar os acontecimentos da implantação do Cadastro Ambiental Rural, a efetivação do Projeto de Lei, após várias prorrogações, para que os produtores rurais se adequarem a legislação. Ainda, segundo Gil (2012, p. 27): “interesse na aplicação, utilização e consequências práticas dos conhecimentos" poderá auxiliar em um estudo de caso.

Inicialmente foi realizada uma análise documental, recorrendo-se a fontes diversas, como relatórios, documentos oficiais, artigos, entre outros. Em seguida procedeu-se ao estudo de caso, uma pesquisa em propriedades rurais que regularizaram a inscrição no Cadastro Ambiental Rural conforme as especificações legais, para verificação de quais seriam os impactos acerca da aplicação da área de preservação permanente e da reserva legal. Ainda, 
realizou-se entrevista com profissionais da engenharia florestal que participaram ativamente da regularização de muitas propriedades rurais junto ao Cadastro Ambiental Rural.

Entrevistas semiestruturas possibilitam a busca da compreensão de um fenômeno. Neste estudo trata-se da aplicação do Cadastro Ambiental Rural. Optou-se pela realização de entrevistas com profissionais da engenharia florestal, que estão diretamente vinculados à legislação vigente, na realização do cadastro das propriedades rurais. Igualmente se estudou os possíveis efeitos econômicos imediatos da implantação do CAR em quatro propriedades rurais do Noroeste gaúcho.

\section{Discussão e Resultados}

O Código Florestal poderá auxiliar no encaminhamento dos passivos ambientais, ou seja, regularizar as propriedades que se encontram ao revés da lei. Para responder a esse desafio, foram criados programas e ferramentas que possam articular os caminhos da regularização ambiental, sendo o Cadastro Ambiental Rural, um mecanismo indicado para o regramento ambiental.

A esperança é de que o Cadastro Ambiental Rural seja um sistema menos burocrático, por ser um procedimento técnico especializado, elaborado pelo órgão ambiental. Porém, para Mattos \& Hercowitz (2011), há compreensão e divergências das propostas com dois tipos de valoração: direta dos serviços ambientais vem da economia ambiental e apoia-se em mecanismos como: a) disposição a pagar; b) direito de propriedade (Teorema de Coase) e c) taxas pigouvianas ${ }^{1}$. Já a valoração indireta origina-se da economia ecológica e busca associar valores culturais e sociais à racionalidade econômica, o que demanda profundas mudanças institucionais, novos instrumentos econômicos e inovadoras metodologias de valoração indireta de serviços ambientais a partir de noções não monetárias.

O Cadastro Ambiental Rural aponta a necessidade de uma regularidade do cadastro para obtenção de financiamentos agrícolas e dos contratos de seguro agrícola. Na pesquisa com os profissionais da engenharia florestal ficou evidenciado a necessidade de valores a serem desembolsados na realização do cadastro, sendo que empréstimos e financiamentos podem deixar de ser auferidos pelos proprietários rurais junto às instituições financeiras, além

\footnotetext{
1 O Imposto de Pigou, conhecido também como "Taxa Pigouviana" ou "Imposto Pigouviano", é uma taxa tributária que tem como objetivo principal a erradicação de externalidades negativas, ou seja, a eliminação de consequências desfavoráveis surgidas através da produção e/ou consumo de bens e serviços.
} 
de outros tipos de contratos ou benefícios que podem ser negados, caso não seja realizada a inscrição no Cadastro Ambiental Rural.

O CAR ainda aponta, segundo os entrevistados, para a regularização das propriedades, com a recuperação, regeneração, recomposição ou compensação ambiental. A compensação ambiental poderá ser feita dentro das propriedades que o produtor já tem, podendo ainda haver a disponibilização do dinheiro do proprietário não regular para o arrendamento de área que esteja sob servidão ambiental ou reserva legal. Para tanto, deve haver manifestação do detentor do imóvel ratificando a compra do seu excedente de reserva legal a ser utilizado por terceiro especificado como compensação de reserva legal.

Além das entrevistas com profissionais da engenharia florestal, foram coletadas informações em quatro propriedades rurais, que indicaram efeitos financeiros específicos acerca do impacto da aplicação do Cadastro Ambiental Rural, levando-se em consideração apenas os cultivos de soja e trigo.

A primeira propriedade rural estudada possui 270,12 hectares em sua área total, e já tem uma área de preservação permanente, que é obrigatório o cumprimento desta, de 20,5 hectares. Ainda, essa propriedade tem 25,7 hectares de área preservada como reserva legal. Ou seja, de 270,12 hectares, os proprietários preservam uma área de 46,2 hectares. Ocorre que, para que essa propriedade atenda à legislação vigente, os proprietários deveriam abandonar uma área maior, com mais 28,3 hectares.

Desta forma, a propriedade do exemplo 01 deixaria 54 hectares sem qualquer tipo de uso e sem render para atender apenas à Reserva Legal. Dessa forma, pegando a média de colheita de soja no município de Catuípe/RS, município onde está localizada a referida propriedade (dado obtido no site da Emater/RS referente ao ano de 2017), que é de 56,7 sacas/hectares, a referida propriedade deixaria de produzir por ano, 3.061,8 sacas de soja. Com o valor do preço da saca de soja no dia 22/07/2019, que é de $\mathrm{R} \$ 68,04$, segundo o site da Agrolink, essa propriedade deixou de faturar em um ano, apenas com a cultura de verão, o valor de R \$ 208.324,87. São R \$ 3.857,87 por hectare não cultivado.

No caso do cultivo de trigo, a média gaúcha produzida nos últimos 10 anos é de 2.142 quilos por hectares, equivalente a 35,7 sacas (Emater, 2019). Assim, a propriedade deixaria de produzir por ano 2.659,65 sacas de trigo. Com o valor da saca de trigo no dia 17/08/2019, em $\mathrm{R} \$ 43,02$, essa propriedade, ao responder as exigências do CAR, deixa de faturar em um ano, apenas com a cultura de inverno, o valor de $\mathrm{R} \$ 114.418,14$. São $\mathrm{R} \$ 1.535,81$ por hectare não cultivado. 
Desta forma, apenas com as duas culturas, a propriedade deixaria de faturar o valor total de $\mathrm{R} \$ 401.829,31$ no ano.

Na segunda propriedade rural estudada, com área total de 1.074 hectares, a mesma já possui 51,03 hectares de área de preservação permanente, tendo ainda 150,89 hectares de vegetação nativa (mato). Porém, a Reserva Legal determinada em lei, alcança uma área de 214,9 hectares. Desta forma, seus proprietários necessitariam abandonar ainda uma área de 64,01 hectares.

Considerando-se que essa propriedade está localizada no município de Chiapetta/RS, onde a produtividade média do ano de 2017 foi de 65,18 sacas de soja por hectare plantado, haveria uma perda anual de 14.007,18 sacas de soja. Em valores, considerando o preço médio da soja em 22/07/2019, que é de $\mathrm{R} \$ 68,04$, essa propriedade deixaria de faturar $\mathrm{R} \$$ 953.048,53. São $\mathrm{R} \$ 4.434,85$ que deixarão de ser recebidos para cada hectare que deixa de ser plantado.

No caso do cultivo de trigo, a média estadual nos últimos 10 anos é de 2.142 quilos por hectare, equivalendo a 35,7 sacas. Assim, a propriedade deixaria de produzir, por ano, 7.671,93 sacas de trigo. Com o valor médio da saca de trigo em R \$ 43,02 (em 17/08/2019), essa propriedade deixa de faturar em um ano, apenas com a cultura de inverno, o valor de $\mathrm{R} \$$ $330.046,43$. Com as duas culturas, a propriedade deixaria de faturar o valor total de $\mathrm{R} \$$ 1.283.094,96 em um ano.

Em uma terceira propriedade rural, localizada no município de Joia/RS, que possui 1.243 hectares para plantio, a mesma deixa 68,4 hectares para preservação permanente. Além dessa área já preservada, é necessário deixar 112,58 hectares preservados como reserva legal. Contudo, essa extensão de terras preservada não é suficiente para que a propriedade rural se encaixe na legislação vigente. Ela precisa de uma área de 136,42 hectares para que a reserva legal seja totalmente composta.

Ora, ao não semear uma área de 249 hectares, que em 2018 tinha uma produtividade de 3.211 quilos de soja por hectare, correspondendo a 53,52 sacos/hectare, os proprietários deixarão de colher 13.326,48 sacos de soja. Pelo valor médio considerado neste trabalho, a propriedade deixa de faturar $\mathrm{R} \$ 906.733,70$.

No caso do cultivo de trigo, considerando que a produtividade média gaúcha dos últimos 10 anos é de 2.142 quilos por hectare, equivalendo a 35,7 sacas/hectare, a propriedade deixa de produzir por ano 8.889,3 sacas de trigo. A partir do valor médio da saca de trigo aqui utilizado, essa propriedade deixa de faturar, em um ano, apenas com a cultura de inverno, o 
valor de $\mathrm{R} \$ 382.417,68$. Com as duas culturas, a propriedade deixa de faturar o valor total de $\mathrm{R} \$ 1.289 .151,39$ no ano.

Uma quarta propriedade, localizada no município de Boa Vista do Cadeado/RS, possui uma área de cultivo de 326 hectares. Assim, ela deixa 8,8 hectares de área de preservação permanente e 9,38 hectares para a reserva legal. Porém, para que esta propriedade se enquadre na legislação vigente, seria necessário que os proprietários da área deixassem mais 56,25 hectares na condição de reserva legal, somando um total de 65,63 hectares.

Em Boa Vista do Cadeado a produtividade média alcançada no ano de 2017 foi de 3.599 quilos de soja por hectare ou 59,98 sacos/hectare. Considerando a área total a ser preservada como reserva legal, deixariam de ser produzidos anualmente, 3.936 sacas de soja. Isso representa um total de $\mathrm{R} \$ 267.838,78$ no ano, a partir do valor médio considerado para a saca de soja. No caso do cultivo de trigo, a média estadual dos últimos 10 anos é de 35,7 sacas/hectare. Assim, a propriedade deixaria de produzir por ano 2.343 sacas de trigo. Com o valor da saca de trigo em $\mathrm{R} \$ 43,02$, essa propriedade deixa de faturar, no ano, apenas com a cultura de inverno, o valor de $\mathrm{R} \$ 100.795,86$. Com as duas culturas, a propriedade deixa de faturar o valor total de $\mathrm{R} \$ 368.634,64 \mathrm{em}$ um ano.

Nos quatro exemplos verificados, para o cumprimento do Cadastro Ambiental Rural, tem-se que, juntos, possuem uma área total de 2.914 hectares. Assim, a área de preservação permanente somaria 148,73 hectares e a área para reserva legal chega a 604,03 hectares. Diante disso, as quatro propriedades, juntas, deixariam de produzir, levando-se em conta uma média de produção de 58,84 sacas de soja por hectare, para atender ao requerido legalmente como área de preservação permanente, um total de 8.751,27 sacas de soja. Para atender à Reserva Legal, serão 35.541,13 sacas de soja. Pelo preço médio da soja, a soma desta quantidade resulta em $\mathrm{R} \$ 595.436,41$ e $\mathrm{R} \$ 2.418 .218,49$, respectivamente, que se deixa de faturar. Assim, serão R \$ 3.013.654,90 que deixarão de circular anualmente.

Por sua vez, em relação à produção de trigo, as propriedades deixariam de produzir, juntas, 21.563,88 sacas para cumprir as exigências legais. Deixariam, portanto, de faturar anualmente R \$ 927.678,12. Somando-se as duas culturas, serão R \$ 3.941.333,02 que não serão faturados nas quatro propriedades somadas. Pode-se imaginar quanto à região deixará de faturar somando-se todas as propriedades de todos os municípios que a compõem.

O que existia, anteriormente à Lei do Cadastro Ambiental Rural, era a Lei no 4.771 de 15 de setembro de 1961, e era chamada de Novo Código Florestal. O primeiro Código Florestal vem da década de 1930, mas sofreu muitas dificuldades em sua implementação (FARIA, n.d). Nessa legislação já havia a separação entre áreas de preservação permanente e 
reserva legal. As áreas de preservação permanente tinham seu tamanho definido de acordo com os rios e/ou cursos d’água que transcorriam na propriedade. Já a reserva legal tinha seu tamanho definido em $20 \%$ da área da propriedade.

Assim, não se pode concluir qual era a área que necessitaria de reserva para preservação permanente e reserva legal para as propriedades utilizadas neste estudo, uma vez que não se possui as informações necessárias para a conclusão desse estudo conforme as leis anteriores à Lei do CAR.

Porém, mesmo sem esses dados, o que fica é que o Novo Código Florestal apesar de ser uma legislação que estava em vigor, na época, ele não tinha aplicação na realidade, já que não havia qualquer tipo de fiscalização por parte do poder público. Desta forma, mesmo que a legislação fosse mais rígida na época ela não possuía aplicação prática. Isso é o maior diferencial quanto ao CAR, que tem seu conteúdo disponibilizado em uma plataforma pública e acessível ao poder público, que poderá fiscalizar as propriedades sem a necessidade de ir até o local que precisa ser fiscalizado.

\section{Considerações Finais}

O objetivo central da pesquisa foi o de identificar algumas consequências imediatas na implantação do Cadastro Ambiental Rural, com destaque para os impactos financeiros, em sua aplicação, nas propriedades rurais, bem como o uso sustentável dos recursos naturais existentes, para a preservação da biodiversidade.

A pesquisa aponta que uso sustentável dos recursos naturais poderá contribuir na redução da poluição do ar, água e solo, regulação de fatores climáticos, regulação da fauna e flora, entre outros ganhos que, mesmo não podendo ser mensurados, devem favorecer em muito ao desenvolvimento socioeconômico das futuras gerações. A questão que se apresenta é como compensar, no imediato, os produtores rurais que, pelo cumprimento da lei, deixarão de gerar recursos elevados em suas propriedades, cujo somatório pode comprometer a economia dos próprios municípios e de regiões inteiras.

Neste sentido, muitas dúvidas ainda pairam sobre aqueles que trabalham com o ambiente rural, sejam os profissionais que atuam junto aos produtores rurais, lhes prestando auxílio e fornecendo instruções, sejam os próprios produtores rurais, os quais não têm segurança para continuar plantando nas áreas agrícolas que sempre foram utilizadas ao longo de muitos anos. 
Por enquanto, não há indicativos, a partir dos exemplos reais trazidos acerca da produção e dos valores que deixarão de ser gerados nas propriedades rurais, se os proprietários serão compensados pelas perdas econômicas que dali resultarão.

Neste sentido, sugere-se, para futuros estudos, verificar como se dá a aplicação da lei no que se refere à Reserva Legal, associando a isso a avaliação do que acontecerá no momento em que as propriedades começarem a ser fiscalizadas mais amiúde, tanto no que diz respeito aos efeitos ambientais quanto aos efeitos econômicos e suas consequências.

\section{Referências}

Agrolink.(2019). Cotações. Website Agrolink. Recuperado: 22 de fevereiro de 2020. https://www.agrolink.com.br/cotacoes/graos/soja/soja-em-grao-sc-60kg

Borges LAC (2013). Seminário de Atualização sobre o Novo Código Florestal. Lavras: Universidade Federal de Lavras.

Brasil. Lei $n^{o}$ 12.651, de 25 de maio de 2012. (2012). Dispõe sobre a proteção da vegetação nativa. http://www.planalto.gov.br/ccivil_03/_Ato2011-2014/2012/Lei/L12651.htm

Bursztyn MA \& Bursztyn M (2013) Fundamentos de Política e Gestão Ambiental: Caminhos para a sustentabilidade. Rio de Janeiro: Editora Garamond.

Cadastro Ambiental Rural Rio Grande Do Sul. Informações. O que é CAR? Recuperado: 20 de janeiro de 2020 http://www.car.rs.gov.br/\#/site/sobreocar

Emater/RS - Ascar. Soja: rendimento médio. Recuperado: 20 de janeiro de 2020 http://www.emater.tche.br/site/arquivos_pdf/serie/serie_4220181107.pdf

Emater/RS - Ascar. Soja: área plantada (ha). Recuperado: 23 de fevereiro de 2020 http://www.emater.tche.br/site/arquivos_pdf/serie/serie_4120181107.pdf

Emater/RS - Ascar. Área, Produção, Rendimento e Valor Bruto da Produção - SOJA (em grão) - RIO GRANDE DO SUL - 1970/2017. Recuperado: 22 de março de 2020 http://www.emater.tche.br/site/arquivos_pdf/serie/serie_4320181120.pdf 
Emater/RS - Ascar. Emater/RS- Ascar estima 1,431 milhão de toneladas de trigo para esta $\begin{array}{lllll}\text { safra. } & \text { Recuperado: } & \text { março de } & 2020\end{array}$ http://www.emater.tche.br/site/multimidia/noticias/detalhenoticia.php?id=28415\#.XVWnwehKjIU

Faria, C. Código Florestal de 1965. Recuperado: 03 de dezembro de 2019 https://www.infoescola.com/ecologia/codigo-florestal-de-1965/

Farinaci, J. S., Ferreira, L. C., \& Batistella, M. (2013). Transição florestal e modernização ecológica: a eucaliptocultura para além do bem e do mal. Ambiente \& Sociedade.

Fonseca, J. J. S. (2002). Metodologia da pesquisa científica. Fortaleza: UEC.

Gil, A. C. (2012) Métodos e técnicas de pesquisa social (p. 27). São Paulo: Atlas.

Graziano, F. (2012). Presidente do Greenpeace, Marina Silva e ex--presidente do INCRA listam 5 prós e contras do novo Código Florestal. Recuperado: 28 de outubro de 2019 http://www.swu.com.br

Jaguszewski, E. D., Gotuzzo, C. C., \& Condorelli, E. M. F. (2014) Capacitação em Cadastro Ambiental Rural: Manual do Treinando. Porto Alegre: SENAR/AR-RS.

Kiviniemi, M. (1985) Public policies anil their trajets: a typological elaboration of the concept of implementation. Paris.

Lynn, L. E. (1980) Designing public policy: a casebook on the role of policy analysis. Santa Monica, Calif.: Goodyear.

Marconi, M. de A., \& Lakatos, E. M. (2012) Metodologia do Trabalho Científico: procedimentos básicos, pesquisa bibliografia, projeto e relatório, publicações e trabalhos científicos. São Paulo: Atlas. 
Ministério Do Meio Ambiente. Brasil. Cadastro Ambiental Rural. Recuperado: 20 de janeiro de 2020 https://www.mma.gov.br/desenvolvimento-rural/cadastro-ambiental-rural.html

Ministério Do Meio Ambiente. Brasil. O que são as áreas de preservação permanente. Recuperado: 29 de fevereiro de 2020 https://www.mma.gov.br/mma-em-numeros/cadastroambiental-rural

Ministério Do Meio Ambiente. Brasil. Reserva legal: proteção necessária ou intromissão do estado? Recuperado: 30 de janeiro de 2020

https://www12.senado.leg.br/noticias/materias/2009/04/29/o-que-sao-as-areas-depreservacao-permanente

Montenegro, C. (2013). O panorama atual da Exigência de Averbação de Reserva Legal. Recuperado: 25 de janeiro de 2020 http://carinacgm.jusbrasil.com.br/

Peters, B. G. (1986) American Public Policy. Chatham, N.J.: Chatham House.

Romeiro, A. R. Economia ou economia política da sustentabilidade? Texto para Discussão. IE/UNICAMP n. 102, set. 2001.

Souza, C. (2003) Políticas públicas: questões temáticas e de pesquisa. Caderno CRH.

Souza, C. (2007) Estado da arte da pesquisa em políticas públicas. In: Hochman, G. et al. Políticas públicas no Brasil. Rio de Janeiro: Fiocruz.

Sparovek, G., Barretto, A., Klug, I., Papp, L., \& Lino, J. (2011) A revisão do Código Florestal brasileiro. São Paulo: Novos Estudos-CEBRAP.

\section{Notas Finais}

O Imposto de Pigou, conhecido também como "Taxa Pigouviana" ou "Imposto Pigouviano", é uma taxa tributária que tem como objetivo principal a erradicação de externalidades negativas, ou seja, a eliminação de consequências desfavoráveis surgidas através da produção e/ou consumo de bens e serviços. 
Research, Society and Development, v. 9, n. 7, e690974687, 2020

(CC BY 4.0) | ISSN 2525-3409 | DOI: http://dx.doi.org/10.33448/rsd-v9i7.4687

Porcentagem de contribuição de cada autor no manuscrito

Argemiro Luís Brum - 25\%

Maria Alice da Costa Beber Goi - 40\%

Nelson José Thesing - 25\%

Luciana Moro de Souza - 10\% 